\title{
Minocycline treatment increases resistance to oxidative stress and extends lifespan in Drosophila via FOXO
}

\author{
Gang Jun Lee ${ }^{1}$, Jin Ju Lim ${ }^{1}$ and Seogang Hyun ${ }^{1}$ \\ ${ }^{1}$ Department of Life Science, Chung-Ang University, Seoul, Korea \\ Correspondence to: Seogang Hyun, email: sghyun@cau.ac.kr \\ Keywords: minocycline, anti-aging, Foxo, Drosophila \\ Received: January 10, $2017 \quad$ Accepted: August 17, $2017 \quad$ Published: September 23, 2017 \\ Copyright: Lee et al. This is an open-access article distributed under the terms of the Creative Commons Attribution License 3.0 \\ (CC BY 3.0), which permits unrestricted use, distribution, and reproduction in any medium, provided the original author and source \\ are credited.
}

\section{ABSTRACT}

Minocycline is a semi-synthetic tetracycline derivative antibiotic that has received increasing attention for its non-antibiotic properties, mainly anti-inflammatory, tumorsuppressive, and neuroprotective effects. Drosophila is a widely used genetically tractable model organism for studying organismal aging by virtue of its short lifespan and ease of cultivation. In this study, we examined the effects of minocycline on Drosophila lifespan and its associated traits. Minocycline-supplemented food significantly extended lifespan in both Canton $S$ and $w^{1118}$ Drosophila strains. The drug-induced lifespan extension was not associated with reduced dietary intake or reduced female fecundity, but rather with increased resistance to an oxidative stressor (hydrogen peroxide). Notably, minocycline's effects on lifespan and resistance to oxidative stress were largely abrogated in Forkhead box $O$ (FOXO) null mutant, and the drug treatment increased the activity of FOXO. These results may further our understanding of minocycline's beneficial effects against several age-associated deteriorations observed in animal models.

\section{INTRODUCTION}

Minocycline

(7-dimethylamino-6desoxytertracycline) is a second-generation, semisynthetic tetracycline analog that has been used for over 30 years to treat various symptoms related to bacterial infections, including acne vulgaris and some sexually transmitted diseases [1, 2]. Minocycline, capable of being easily absorbed into the body and displaying a long half-life and excellent tissue penetration, shows a better pharmacokinetic profile than some tetracyclines when used orally [3]. Moreover, minocycline is a highly lipophilic molecule that can easily pass through the bloodbrain barrier $[2,4,5]$.

Recent work has focused on the non-antibiotic properties of minocycline, such as its anti-inflammatory and anti-apoptotic activities, as well as inhibition of proteolysis and suppression of cancer metastasis [6-9]. These features support the potential use of the drug in the treatment of rheumatoid arthritis, inflammatory bowel syndromes, scleroderma, aortic aneurysms, and malignant tumors $[6,10,11]$. Furthermore, due to its ability to cross the blood-brain barrier to reach the central nervous system, minocycline has been shown to be an effective therapeutic option in various experimental models of brain injury, as well as in several neurodegenerative conditions such as Parkinson's disease, Huntington's disease, amyotrophic lateral sclerosis, and Alzheimer's disease [12-17]. Although the mechanism of action underlying the antibiotic properties of minocycline is largely related to its ability to bind to the bacterial $30 \mathrm{~S}$ ribosomal subunit, thereby inhibiting protein synthesis, the exact mechanisms of action underlying its non-antibiotic properties (antiinflammatory, immunomodulatory, and neuroprotective effects), are not yet understood.

Aging can largely be regarded as the progressive decline in physiological integrity and function, which includes molecular interactions, cellular functions, tissue structure and function, and systemic physiological homeostasis [18]. This age-associated decline is 
accompanied by a progressive increase in mortality and a spectrum of age-related conditions such as diabetes, cardiovascular diseases, and neurodegenerative disorders. However, genetic studies from several model organisms have established that aging is a plastic process, such that manipulation of even a single gene among several conserved genetic pathways, such as insulin/TOR signaling, can dramatically modify the rate of aging and extend lifespan [19]. Forkhead box $O(F O X O)$ is the transcription factor acting as downstream effector of insulin signaling; FOXO activity has been shown to be associated with stress resistance and lifespan extension in many organisms including human [19].

Drosophila melanogaster has been widely used in aging research for its relatively short lifespan (approximately 3 months), low maintenance requirements, and large number of available experimental tools that enable in vivo genetic manipulation. Moreover, more than $75 \%$ of known human disease genes, covering a broad range of disorders, have fly homologs [20]. These characteristics highlight Drosophila as an ideal model organism for investigating the mechanisms of aging and for developing therapeutic interventions that treat human aging and its associated pathologies.

In this study, we tested the potential effects of minocycline on the aging process in Drosophila. Feeding minocycline to adult Drosophila significantly extended lifespan, which was consistently seen in both Canton $S$ and $w^{1118}$ Drosophila strains regardless of sex. Minocyclineinduced extension of lifespan in the $w^{1118}$ strain, which is defective in intracellular transport of tryptophan [21], does not support a previously suggested hypothesis that the longevity effect of the drug was conferred via the kynurenine pathway $[22,23]$. We found that minocycline treatment neither decreased the rate of food consumption nor impaired the fecundity of flies. However, the flies fed minocycline exhibited increased resistance to hydrogen peroxide treatment, associating a long lifespan with oxidative stress resistance. Notably, the drug's effects on lifespan and oxidative stress resistance were largely absent by mutation of $F O X O$, a key gene in the aging and stress resistance pathways; minocycline treatment generally increased the activity of FOXO, providing insights of minocycline's underlying mechanism.

\section{RESULTS}

\section{Minocycline feeding extends lifespan in both Canton $S$ and $w^{1118}$ Drosophila strains}

We examined the effect of minocycline on the lifespan of adult Drosophila from two commonly used strains, Canton $S$ and $w^{1118}$. Previous studies noted the effect of minocycline treatment on the Oregon $R$ strain of Drosophila, showing that the drug can extend lifespan in this strain $[22,24]$. We found that minocycline at either a low dose $(0.05 \mathrm{mM})$ or high dose $(0.36 \mathrm{mM})$ significantly increased lifespan in Canton $S$ flies, and this effect was seen consistently in both male and female flies (Figure 1 and Supplementary Figure 1). Male Canton $S$ flies fed normal food had a median lifespan of $50.29 \mathrm{~d}$, which increased by $26.7 \%$ (63.71 d) or by $15.7 \%(58.18$ d) with a low dose $(0.05 \mathrm{mM})$ or high dose $(0.36 \mathrm{mM})$ of minocycline, respectively. Female Canton $S$ flies fed normal food had a median lifespan of $60.6 \mathrm{~d}$, which increased by $13.6 \%(68.87 \mathrm{~d})$ or by $7.7 \%(65.26 \mathrm{~d})$ with a low dose $(0.05 \mathrm{mM})$ or high dose $(0.36 \mathrm{mM})$ of minocycline, respectively. In both male and female flies, a low dose of minocycline resulted in more pronounced effects of lifespan extension than the high dose, suggesting that lifespan-extending effects of minocycline in Drosophila can be maximized by determining the optimum dose. Moreover, although lifespan was extended in both male and female flies by minocycline treatment, male flies exhibited more robust extension of lifespan than female flies.

Next, we examined the longevity effects of minocycline in the $w^{1118}$ Drosophila strain. Similar to findings in Canton $S$ flies, we found that the lifespan of $w^{1118}$ flies fed minocycline at either the low or high dose increased significantly, and this effect was seen in both male and female flies (Figure 2 and Supplementary Figure 2). Male $w^{1118}$ flies fed the control food had a median lifespan of $39.95 \mathrm{~d}$, which increased by $16.9 \%$ (46.69 d) or by $6.0 \%(42.36 \mathrm{~d})$ with a low or high dose of minocycline, respectively. Female $w^{1118}$ flies fed the control food had a median lifespan of $37.87 \mathrm{~d}$, which increased by $22.9 \%$ (46.53 d) or by $15.6 \%$ (43.79 d) when treated with a low or high dose of minocycline, respectively. As was the case with Canton $S$ flies, $w^{1118}$ flies also exhibited a more robust lifespan extension with a low dose of minocycline $(0.05 \mathrm{mM})$. Interestingly, however, the more pronounced minocycline effect on lifespan in males seen in Canton $S$ flies was not seen in $w^{1118}$ flies. Furthermore, minocycline treatment appeared to more strongly increase median lifespan than maximum lifespan in female $w^{1118}$ flies, which contrasts with the similar effects of the drug on median and maximum lifespan seen in male $w^{1118}$ and Canton $S$ flies.

Since previous studies showed that minocycline treatment increased locomotive activity in Oregon $R$ male flies, we tested whether similar effects of the drug were also seen in Canton $S$ and $w^{1118}$ flies. We found that minocycline stimulated the locomotive activity more strongly in male flies than in female flies and in Canton $S$ flies than $w^{1118}$ flies; minocycline failed to increase locomotive activity in $w^{1118}$ female flies (Supplementary Figure 3).

Taken together, these results suggest that minocycline treatment can extend lifespan and improve motor activity in Drosophila strains with a broad spectrum of genetic backgrounds. The observations in the $w^{1118}$ 
strain also indicate that the drug can exert longevity effects independently of the kynurenine pathway (see below).

\section{Minocycline feeding extends lifespan in germ- free $w^{1118}$ Drosophila strains}

We then investigated whether the lifespan extending effects of minocycline was due to its antibiotic effects. To do this, we established the germ-free rearing condition of Drosophila and performed similar experiments of monitoring lifespan as above. We found that the lifespan of germ free $w^{1118}$ flies fed minocycline at either the low or high dose still increased significantly and this effect was seen in both male and female flies (Figure 3). Male germ-free $w^{1118}$ flies fed the control food had a median lifespan of $44.05 \mathrm{~d}$, which increased by $7.8 \%$ (47.52 d) or

\section{J Canton s}
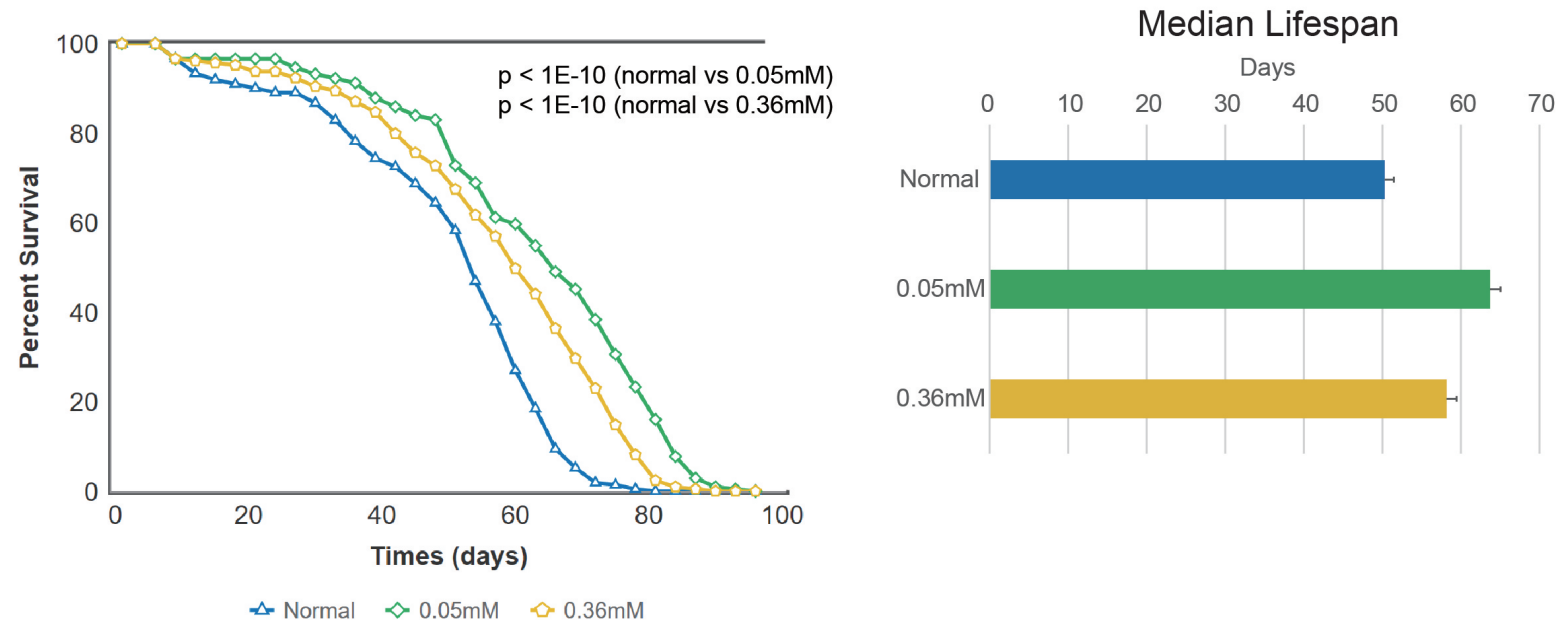

\section{+ Cantons}
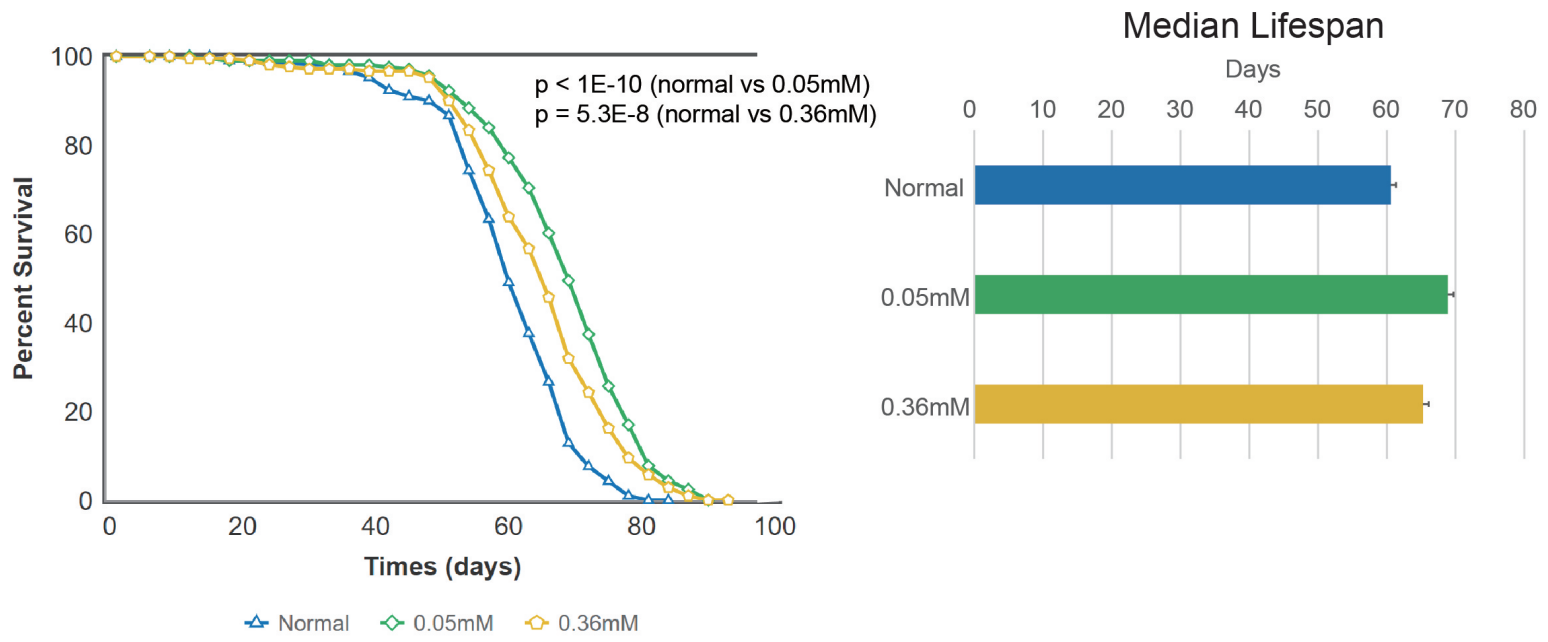

Figure 1: Minocycline extends lifespan in Canton $\boldsymbol{S}$ Drosophila strain. Minocycline treatment $(0.05 \mathrm{mM}$ and $0.36 \mathrm{mM})$ extends lifespan of Canton $S$ flies, as shown by the survival curve (left) and by quantification of median lifespan (right). A more pronounced lifespan extension was induced by the low dose $(0.05 \mathrm{mM})$. The longevity effect of the drug was seen in both male (upper panel) and female (lower panel) flies. For male flies, $\mathrm{n}=224$ (normal), $\mathrm{n}=222(0.05 \mathrm{mM}), \mathrm{n}=225(0.36 \mathrm{mM}) ; p<1.0 \times 10^{-10}$ (both normal vs. $0.05 \mathrm{mM}$ and normal vs. $0.36 \mathrm{mM})$. For female flies, $\mathrm{n}=226$ (normal), $\mathrm{n}=223(0.05 \mathrm{mM}), \mathrm{n}=220(0.36 \mathrm{mM}) ; p<1.0 \times 10^{-10}$ (normal vs. $\left.0.05 \mathrm{mM}\right), p=5.3 \times$ $10^{-8}$ (normal vs. $0.36 \mathrm{mM}$ ). $p$-values for lifespan curves were calculated by the log-rank test. All lifespan experiments were repeated with similar results; representative experiments are shown. Data for median lifespan are presented as mean \pm SEM. 
by $4.4 \%$ (46.02 d) with a low or high dose of minocycline, respectively. Female germ-free $w^{1118}$ flies fed the control food had a median lifespan of $39.05 \mathrm{~d}$, which increased by $7.8 \%(42.10 \mathrm{~d})$ or by $4.2 \%(40.71 \mathrm{~d})$ when treated with a low or high dose of minocycline, respectively. These results indicate that lifespan extension induced by minocycline treatment is not mainly due to germ-free effect, which is consistent with our observation that the same dose of tetracycline treatment as minocycline failed to increase Drosophila lifespan (Supplementary Figure 4). It is noted that lifespan extending effects of minocycline were less dramatic in germ-free flies, raising the possibility that minocycline may also influence Drosophila lifespan through modulating microbiota.

\section{$\delta^{1} w_{1118}$}
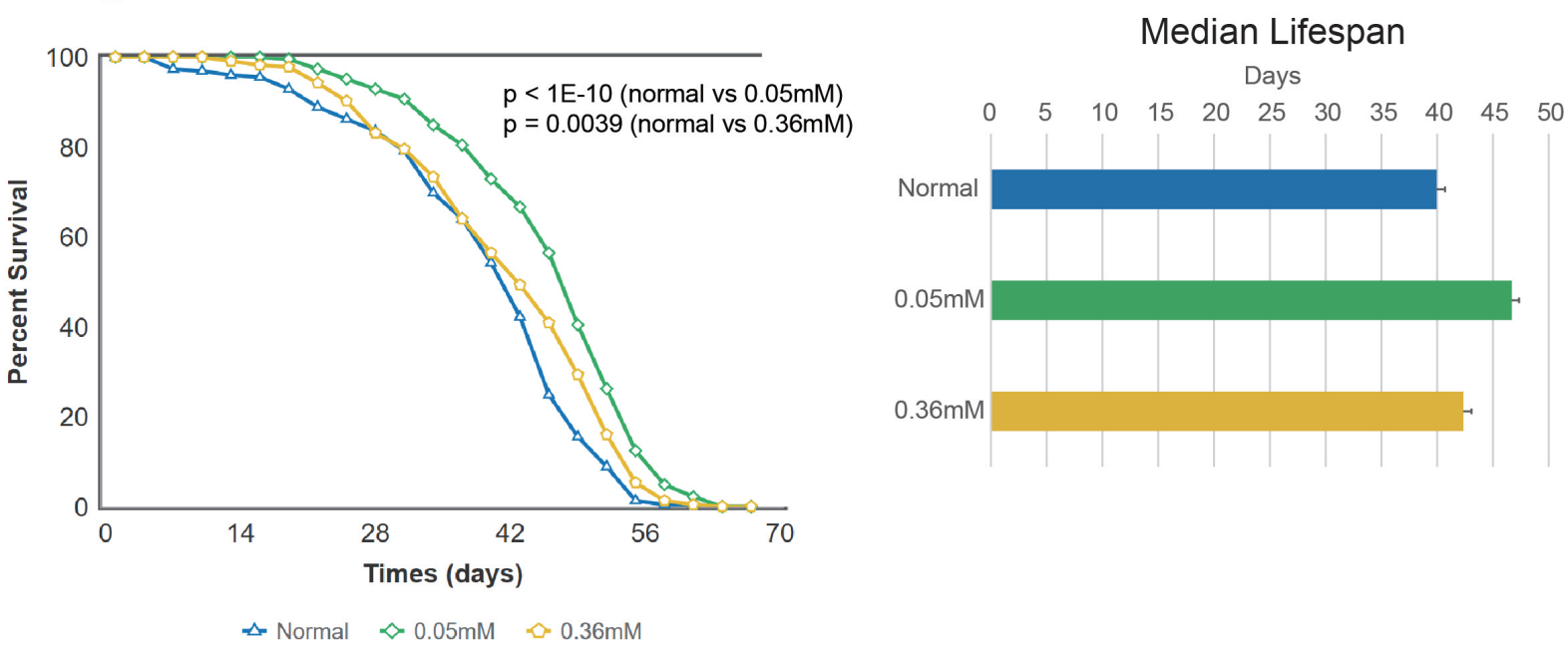

우 w1118
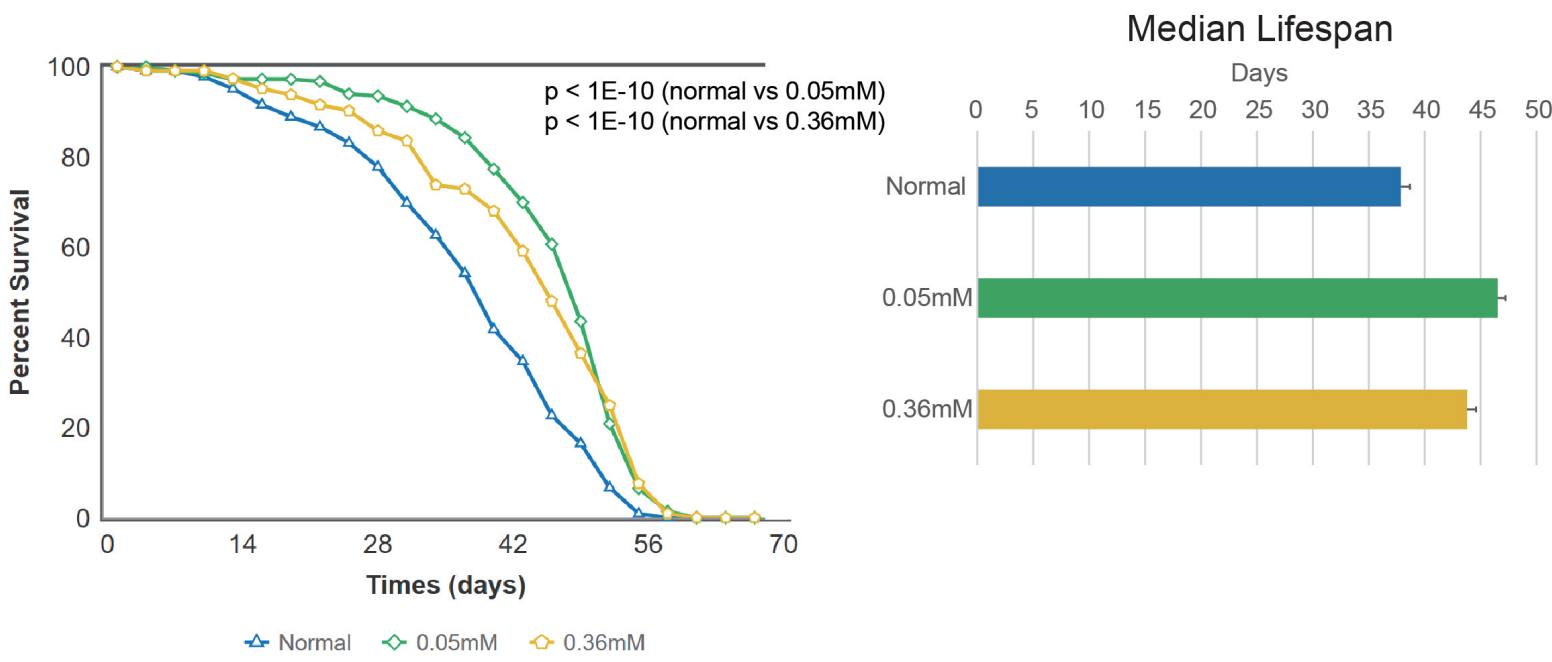

Figure 2: Minocycline extends lifespan in $\boldsymbol{w}^{1118}$ Drosophila strain. Minocycline treatment $(0.05 \mathrm{mM}$ and $0.36 \mathrm{mM})$ extends lifespan of $w^{1118}$ flies, as shown by the survival curve (left) and by quantification of median lifespan (right). A more pronounced lifespan extension was induced by the low dose. The longevity effect of the drug was seen in both male (upper panel) and female (lower panel) flies. For male flies, $\mathrm{n}=228$ (normal), $\mathrm{n}=230(0.05 \mathrm{mM}), \mathrm{n}=220(0.36 \mathrm{mM}) ; p<1.0 \times 10^{-10}$ (normal vs. $\left.0.05 \mathrm{mM}\right), p=0.0039$ (normal vs. 0.36 $\mathrm{mM}$ ). For female flies, $\mathrm{n}=225$ (normal), $\mathrm{n}=232(0.05 \mathrm{mM}), \mathrm{n}=220(0.36 \mathrm{mM}) ; p<1.0 \times 10^{-10}$ (both normal vs. $0.05 \mathrm{mM}$ and normal vs. $0.36 \mathrm{mM}) . p$-values for lifespan curves were calculated by the log-rank test. All lifespan experiments were repeated with similar results; representative experiments are shown. Data for median lifespan are presented as mean $\pm \mathrm{SEM}$. 


\section{Minocycline feeding does not decrease dietary consumption or fecundity}

Dietary restriction has been considered a reliable means of extending animal lifespan [18, 19]. It is possible that the minocycline-containing food was less palatable to Drosophila, resulting in lifespan extension due to reduced dietary intake. We investigated the food consumption rate using a food dye. We found that the amount of food consumed did not differ significantly overall when the food contained minocycline (Figure 4A), although food intake of 5-day-old flies decreased slightly when the food contained a high dose of minocycline $(0.36 \mathrm{mM})$, a phenomenon not observed in 20-day-old flies. Notably, a low dose of minocycline $(0.05 \mathrm{mM})$, which had exerted the strongest effect on lifespan, did not significantly affect

\section{\.1118 (Germ-Free)}

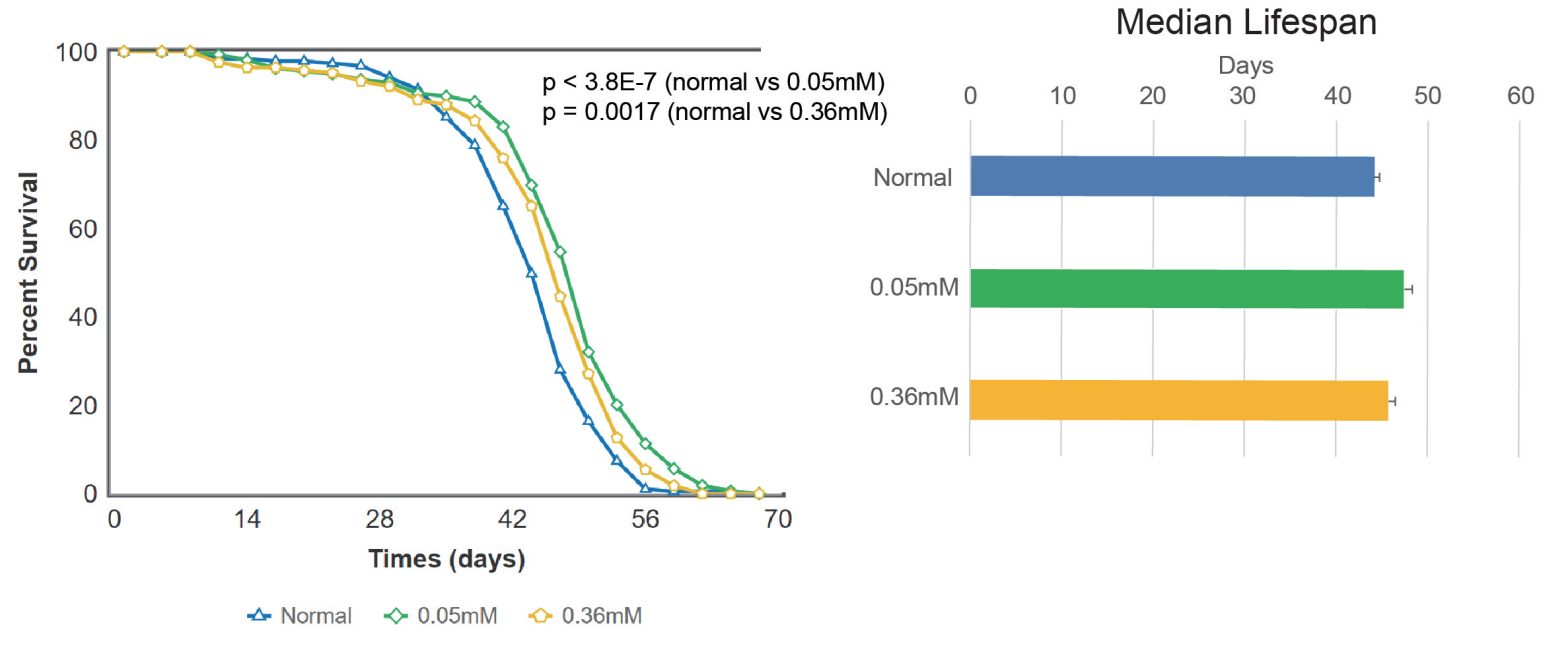

Y w1118 (Germ-Free)

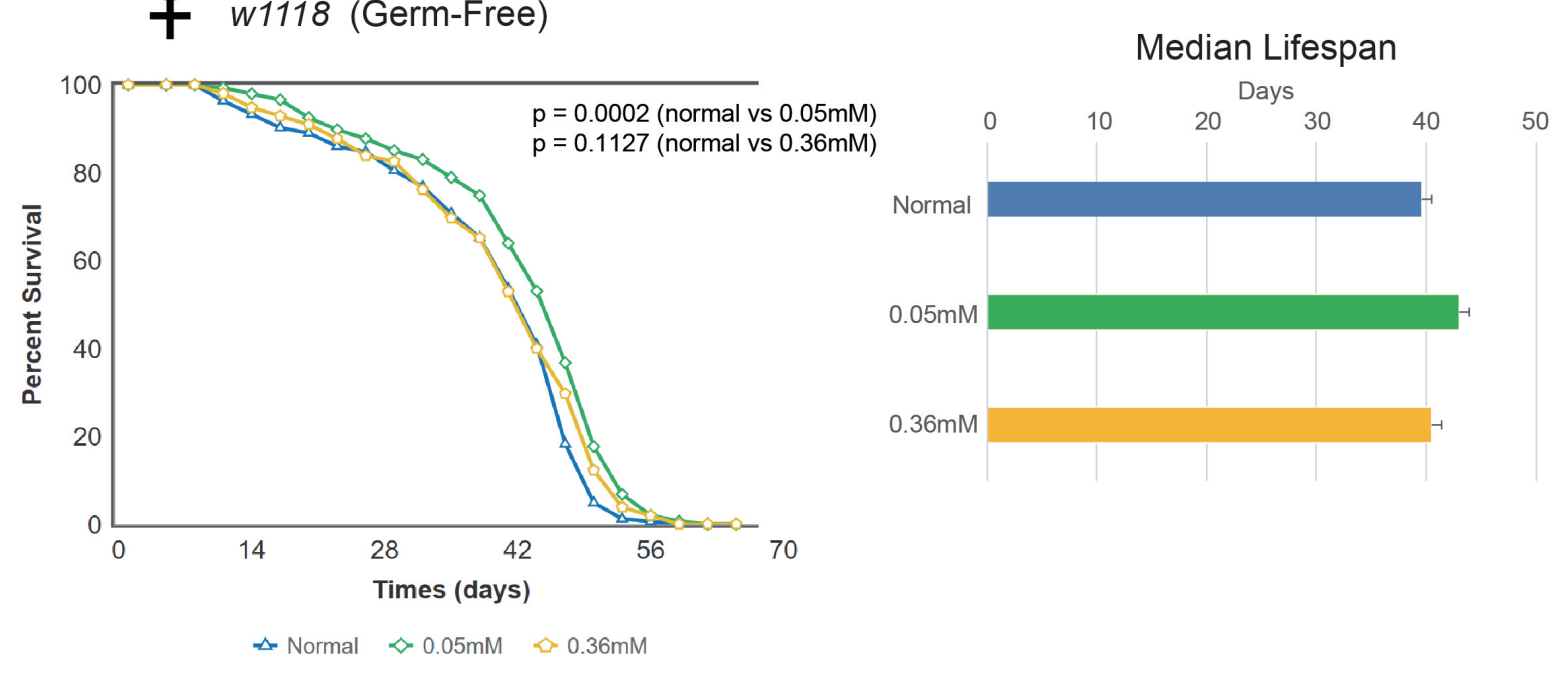

Median Lifespan

Figure 3: Minocycline extends lifespan in germ-free $\boldsymbol{w}^{\text {I118 }}$ Drosophila strain. Minocycline treatment $(0.05 \mathrm{mM}$ and $0.36 \mathrm{mM})$ extends lifespan of germ-free $w^{l 118}$ flies, as shown by the survival curve (left $)$ and by quantification of median lifespan (right). A more pronounced lifespan extension was induced by the low dose. The longevity effect of the drug was seen in both male (upper panel) and female (lower panel) flies. For male flies, $\mathrm{n}=100$ (normal), $\mathrm{n}=100(0.05 \mathrm{mM}), \mathrm{n}=100(0.36 \mathrm{mM}) ; \mathrm{p}<3.8 \times 10^{-7}$ (normal vs. $0.05 \mathrm{mM}$ ), $\mathrm{p}=0.0017$ (normal vs. $0.36 \mathrm{mM}$ ). For female flies, $\mathrm{n}=100$ (normal), $\mathrm{n}=100(0.05 \mathrm{mM}), \mathrm{n}=100(0.36 \mathrm{mM}) ; \mathrm{p}=0.0002$ (normal vs. 0.05 $\mathrm{mM}$ ), $\mathrm{p}=0.1127$ (normal vs. $0.36 \mathrm{mM}$ ). $\mathrm{p}$-values for lifespan curves were calculated by the log-rank test. All lifespan experiments were repeated with similar results; representative experiments are shown. Data for median lifespan are presented as mean \pm SEM. 
the rate of food consumption in either 5-day-old and 20-day-old flies. This finding negates the possibility that minocycline-induced lifespan extension in Drosophila results from reduced food intake.

Some long-lived animals exhibit reduced reproductive activity and hence produce fewer progenies. Lifespan extension following a removal of germline cells has been observed in several animal models [18, 19]. We investigated whether minocycline treatment extends lifespan by attenuating fecundity in flies. Egg counts during the course of aging revealed that fecundity of female flies was slightly decreased by a high dose of minocycline $(0.36 \mathrm{mM})$. However, it was largely unaffected by a low dose of minocycline $(0.05 \mathrm{mM})$, the concentration that exerted the strongest longevity effect (Figure 4B). This finding indicates that the longevity effect of minocycline is not attributable to the inhibition of reproductive activity in Drosophila.

\section{Minocycline feeding increases resistance to oxidative stress}

Long-lived mutant animals frequently exhibit higher resistance to oxidative stress $[18,19]$. We examined whether minocycline treatment could confer resistance to oxidative stress in Drosophila. We found that flies
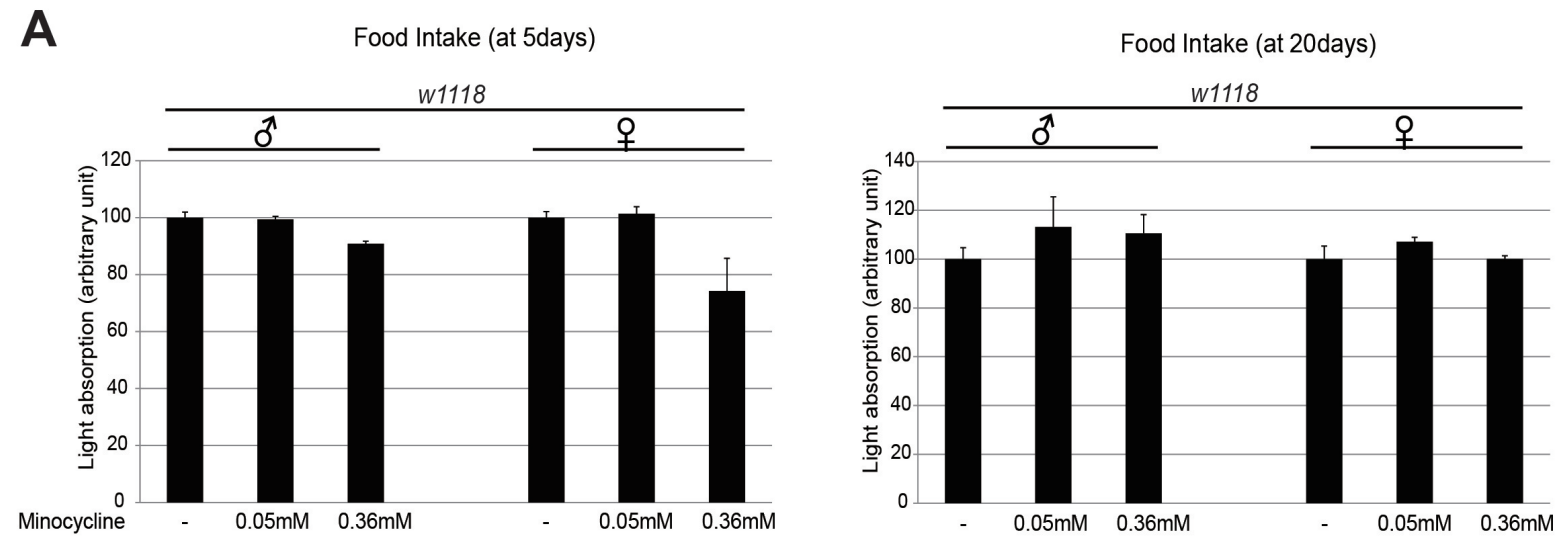

B

w1118

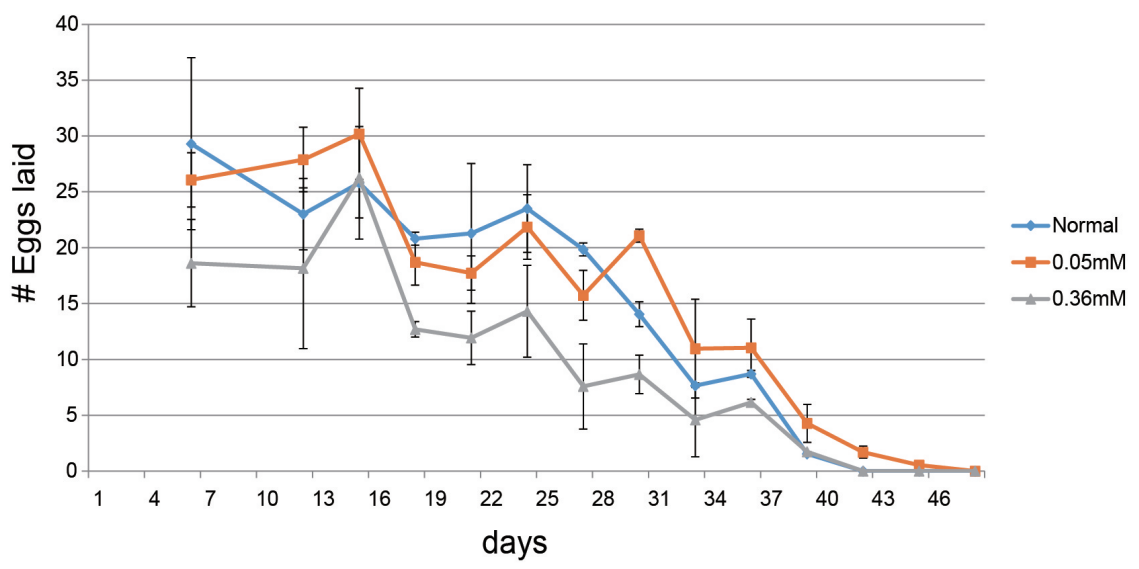

Figure 4: Minocycline treatment barely affects food intake and female fly fecundity. (A) Food intake did not differ between flies exposed to a low $(0.05 \mathrm{mM})$ or high $(0.36 \mathrm{mM})$ dose of minocycline and flies not exposed to minocycline. Food intake was quantified using blue-dye labeling, the accumulation of which in fly bodies was measured with fly extracts. Two different age groups ( $5 \mathrm{~d}$ and $20 \mathrm{~d}$ ) were examined. $\mathrm{n}=10$ per replicate. (B) Egg numbers did not differ between female flies exposed to a low dose $(0.05 \mathrm{mM})$ of minocycline and flies not exposed to minocycline. The number of eggs laid decreased slightly when flies were exposed to a high dose (0.36 mM) of minocycline. For total number of eggs, 198.8 (normal), $191.4(0.05 \mathrm{mM}), 96.4(0.36 \mathrm{mM}) . \mathrm{n}=15$ per replicate. Three biological replicates were analyzed. Data are presented as mean \pm SEM. 
treated with minocycline became more resistant to hydrogen peroxide, dying less often than flies not treated with minocycline (Figure 5). This minocycline-induced resistance to reactive oxygen species (ROS) was seen in both male and female flies. Interestingly, fly resistance to hydrogen peroxide appeared to be more robust following a high dose of minocycline $(0.36 \mathrm{mM})$, contrasting with the stronger effect of a low dose $(0.05 \mathrm{mM})$ on longevity.

\section{Minocycline-induced lifespan extension and ROS resistance are abrogated by $\mathrm{FOXO}$ mutation}

The FOXO transcription factor is involved in a variety of cellular processes to regulate organismal physiology, and is a major determinant of animal lifespan [25]. FOXO activation mediates the lifespan-extending effects of attenuated insulin/insulin-like growth factor-like signaling, and elicits cellular and organismal resistance to various stressors, including oxidative stimuli [19, 25]. We wanted to know whether lifespan extension and resistance to oxidative stress induced by minocycline treatment in Drosophila involve FOXO. To confirm whether minocycline treatment exerts its lifespan-extending and stress-resistance effects via $\mathrm{FOXO}$, a $F O X O$-null mutant fly $\left(F O x O^{21 \text { rev6A }}\right)$ was used. We found that minocycline failed to extend lifespan in the $F O X O$-null fly (Figure 6A), in contrast with the observations in Oregon $R[22,24]$, Canton $S$ (Figure 1), and $w^{1118}$ (Figure 2) flies. Failure to extend lifespan was seen in both male and female mutant flies, regardless of white gene mutation (Supplementary Figure 5). Minocycline effects on resistance to oxidative stress were also examined in the $F O X O$-null mutant flies. Consistent with the lifespan findings, minocycline-induced resistance to hydrogen peroxide was largely abrogated in FOXO-null mutant flies, although a marginal increase in resistance was seen in female flies (Figure 6B). Taken together, these results indicate that minocycline's effects on lifespan and oxidative stress resistance are mediated by FOXO in Drosophila.

\section{Minocycline feeding increases FOXO expression}

The critical dependence of FOXO in the minocycline's effects on oxidative stress resistance and lifespan extension led us to test whether the drug treatment has any influence on FOXO activity. We found that there was a general trend in increase of mRNA expression of FOXO target genes, such as $I n r$ and $4 E-B P$, as well as $F O X O$ gene itself when flies were fed minocycline in both normal and stress condition (Figure 7A, 7B, and Supplementary Figure 6). Notably, this trend of FOXO activation was seen across various tissues such as head, thoracic muscle, and abdominal fat body tissues, and this phenomenon was consistently seen in both male and female flies. To further explore the underlying mechanism, the levels of activated form of Akt and JNK in parallel with FOXO protein were examined by western blot. We found that minocycline treatment consistently increased the level of FOXO protein throughout the tissues examined, but the drug treatment marginally affected the level of activated form of Akt and JNK (Figure 7C). Thus, it appears that minocycline increases the activity of FOXO independently of Akt or JNK. Consistent with the effects of minocycline on fly lifespan and FOXO expression, ubiquitous overexpression of FOXO increased the Drosophila lifespan (Supplementary Figure 7). Intriguingly, extended lifespan of the fly overexpressing FOXO was further increased by minocycline treatment (Supplementary Figure 7). Since minocycline treatment increases FOXO transcript level, this result indicates that minocycline treatment may stimulate FOXO activity in both transcriptional and post-transcriptional manners. Altogether, these results support the notion that minocycline-induced enhancement of FOXO may confer resistance to oxidative stress and extend lifespan in Drosophila.

\section{DISCUSSION}

Since minocycline was first produced in the 1960s, it has been used to treat a broad range of symptoms related to bacterial infections such as acne vulgaris. In recent years, attention has been paid to its further effectiveness in treating various pathological conditions not associated with bacterial infections. Many studies have demonstrated that minocycline can suppress inflammatory disorders, tumorigenesis, and angiogenesis [6-9, 26]. Notably, the ability of minocycline to cross the blood-brain barrier encourages the investigation of the drug as a potential therapeutic agent for many neurological disorders, such as Alzheimer's disease, amyotrophic lateral sclerosis, Huntington's disease, and Parkinson's disease [13-17]. Although minocycline's curative potential for various pathological conditions has been shown, the underlying mechanisms are still unclear. In this study, we used Drosophila to investigate the effects of minocycline on the aging process and their potential underlying mechanisms. We found that flies treated with minocycline lived longer than controls. These effects were seen in two Drosophila strains, and were independent of sex. The longevity effect of minocycline in the $w^{1118}$ strain was intriguing, since minocycline's effect was previously suggested to be dependent of the kynurenine pathway $[22,23]$, which is compromised in $w^{1118}$ strain by mutation of white, a gene encoding tryptophan transporter [21].

To explore the underlying mechanism of minocycline's effects, its influences on food intake, reproductive activity, and resistance to oxidative stress were examined as traits often associated with lifespan modification. We found that neither food consumption nor fecundity were significantly affected; however, minocycline increased resistance to an oxidative stimulus, 
hydrogen peroxide. Notably, minocycline effects on longevity and oxidative stress resistance were largely abolished in FOXO-null mutant flies, and the activity of FOXO increased following minocycline treatment. Altogether, these results suggest that minocycline treatment in Drosophila enhances FOXO activity, thereby conferring resistance to oxidative stress and extending lifespan.

Several molecular targets of minocycline have been proposed to explain the non-antibiotic properties of the drug. It has been shown that minocycline physically interacts with apoptotic protease activating factor 1 (Apaf-1), which inhibits caspase activation and

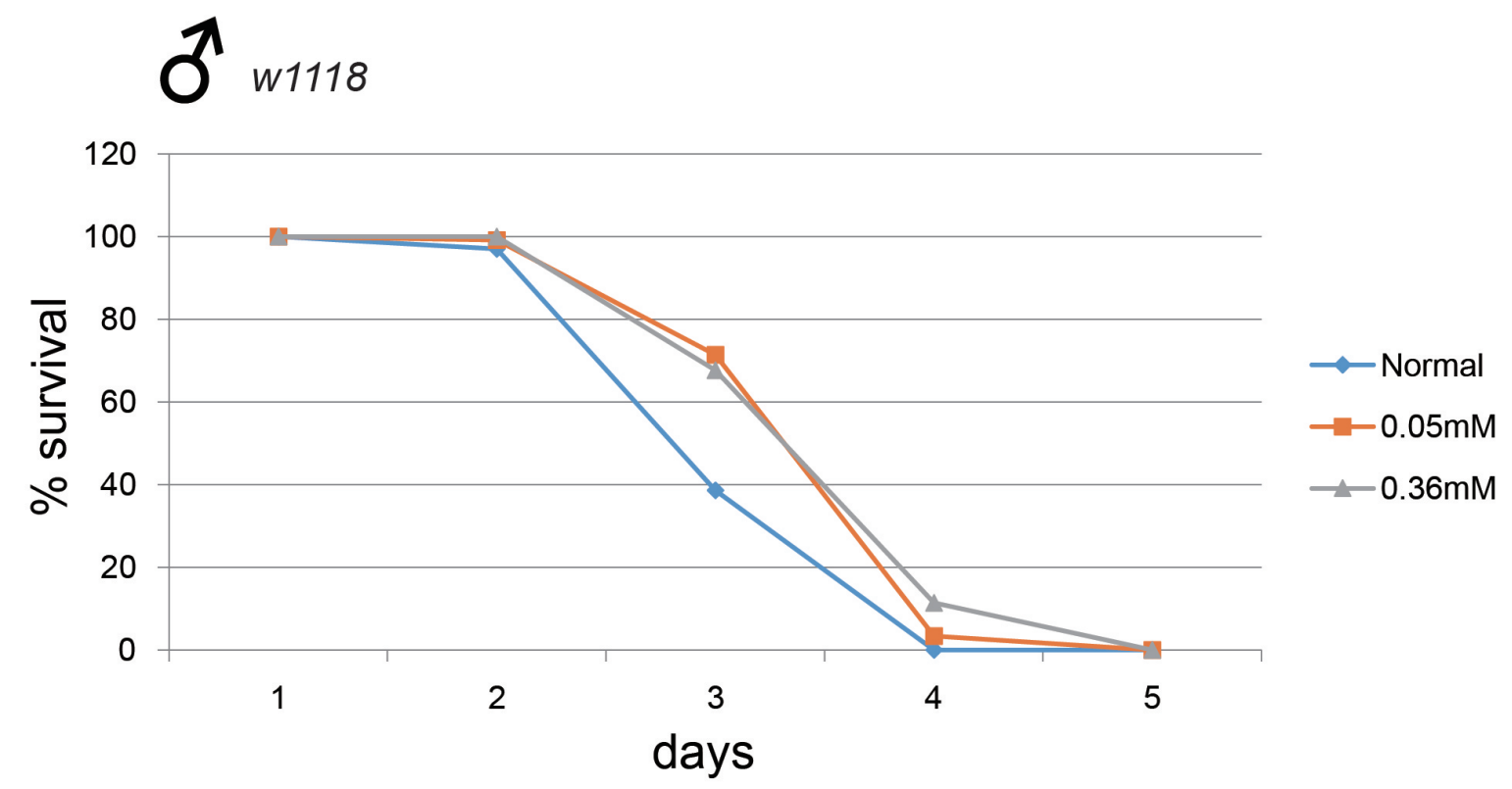

P $w 1118$

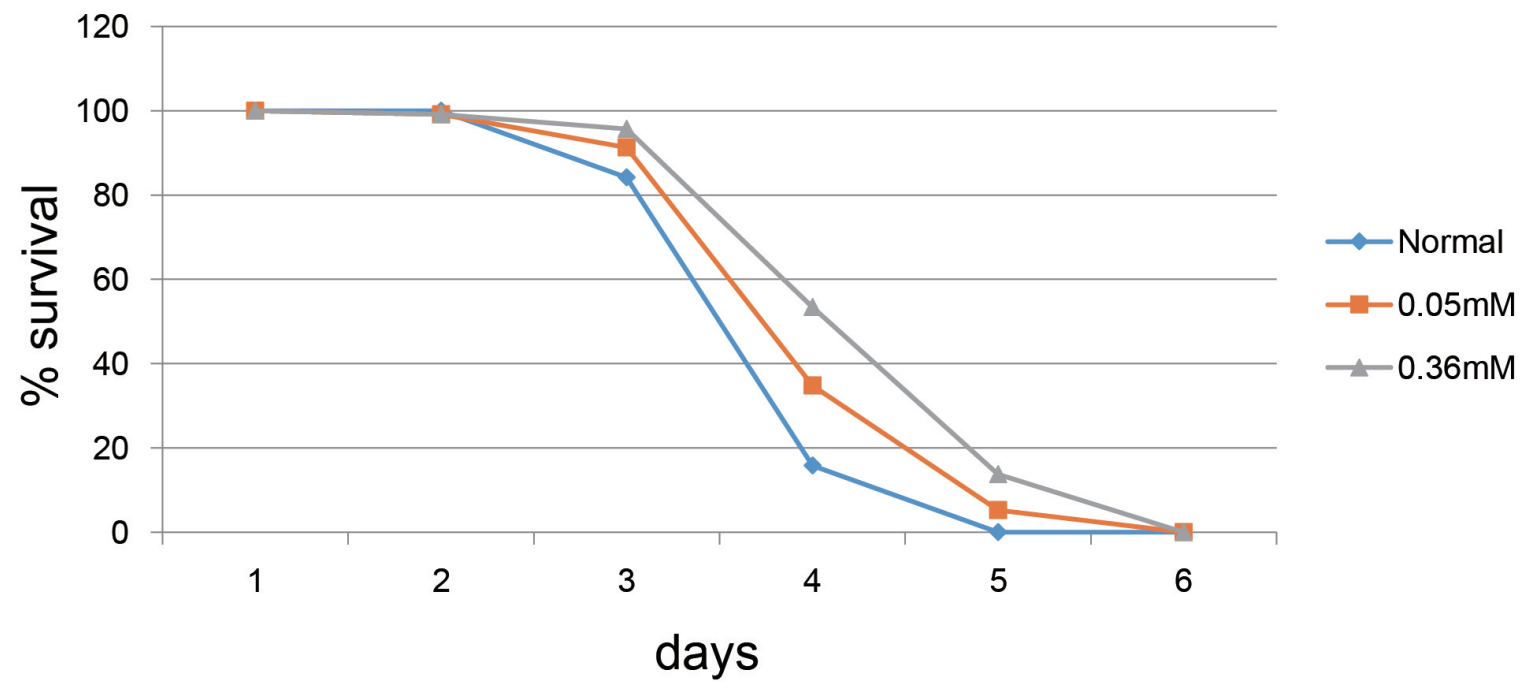

Figure 5: Minocycline treatment increases resistance to oxidative stress. Flies fed minocycline showed a greater resistance to hydrogen peroxide than control flies. This phenomenon was observed in both male (upper panel) and female (lower panel) flies. A high dose $(0.36 \mathrm{mM})$ of minocycline appears to confer greater resistance to oxidative stress. For male flies, $\mathrm{n}=101(\mathrm{normal}), \mathrm{n}=119(0.05 \mathrm{mM})$, $\mathrm{n}=105(0.36 \mathrm{mM}) ; p=3.7 \times 10^{-7}$ (normal vs. $\left.0.05 \mathrm{mM}\right), p=5.9 \times 10^{-7}$ (normal vs. $\left.0.36 \mathrm{mM}\right)$. For female flies, $\mathrm{n}=101($ normal), $\mathrm{n}=115$ $(0.05 \mathrm{mM}), \mathrm{n}=116(0.36 \mathrm{mM}) ; p=0.0004$ (normal vs. $0.05 \mathrm{mM}), p<1.0 \times 10^{-10}$ (normal vs. $0.36 \mathrm{mM}$ ). $p$-values for lifespan curves were calculated by the log-rank test. All lifespan experiments were repeated with similar results; representative experiments are shown. 
A ठFOXO

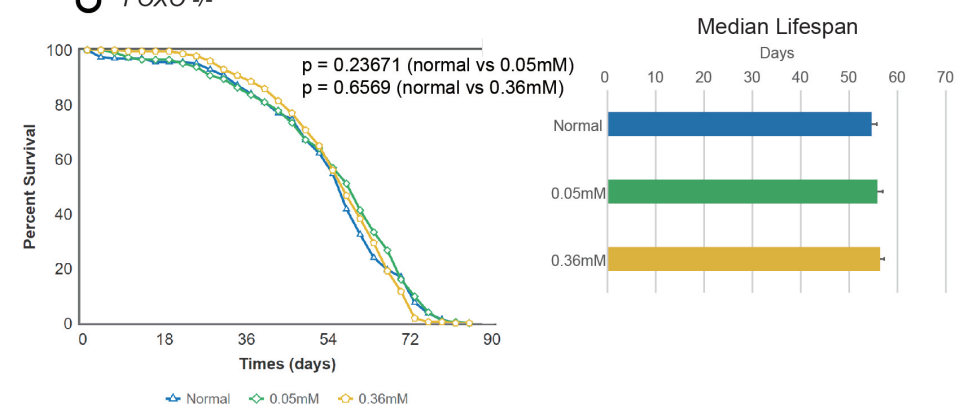

$\diamond$ Normal $\diamond 0.05 \mathrm{mM} \diamond 0.36 \mathrm{mM}$

Q FOXO \%
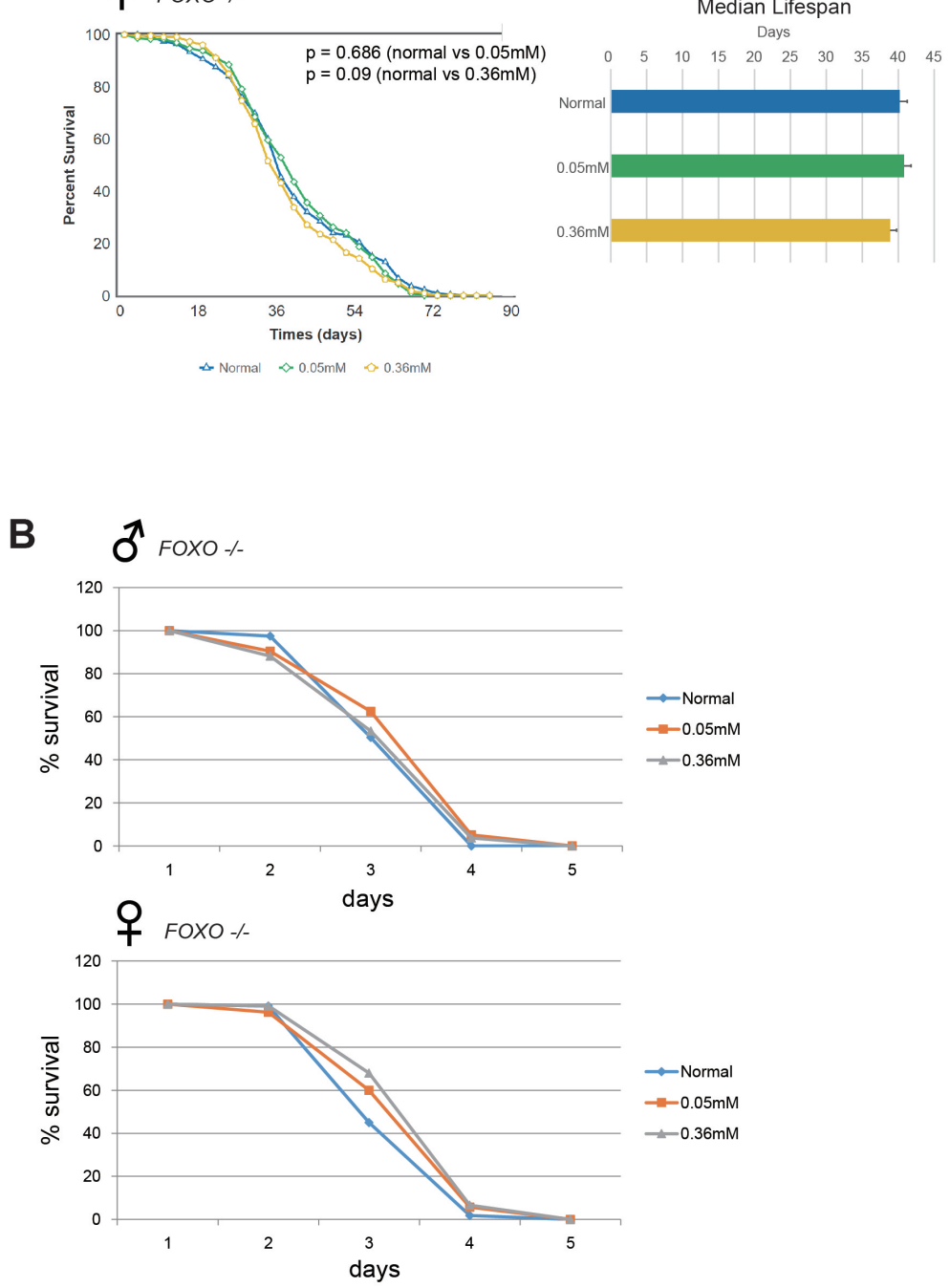

Figure 6: Minocycline fails to extend lifespan and barely increases resistance to oxidative stress in FOXO-null flies. (A) Minocycline treatment $(0.05 \mathrm{mM}$ and $0.36 \mathrm{mM})$ failed to extend lifespan in $F O X O$-null mutant flies, as shown by the survival curve (left) and by quantification of median lifespan (right). The failure to extend lifespan was seen in both male (upper panel) and female (lower panel) flies. For male flies, $\mathrm{n}=210$ (normal), $\mathrm{n}=220(0.05 \mathrm{mM}), \mathrm{n}=223(0.36 \mathrm{mM}) ; p=0.23671$ (normal vs. $0.05 \mathrm{mM}), p=0.6569$ (normal vs. $0.36 \mathrm{mM}$ ). For female flies, $\mathrm{n}=223$ (normal), $\mathrm{n}=228(0.05 \mathrm{mM}), \mathrm{n}=210(0.36 \mathrm{mM}) ; p=0.686$ (normal vs. $0.05 \mathrm{mM}), p=$ 0.09 (normal vs. $0.36 \mathrm{mM}$ ). $p$-values for lifespan curves were calculated by the log-rank test. All lifespan experiments were repeated with similar results; representative experiments are shown. Data for median lifespan are presented as mean \pm SEM. (B) Male FOXO-null mutants fed minocycline did not differ from controls (no minocycline) in sensitivity to hydrogen peroxide (upper panel). Resistance to hydrogen peroxide was slightly higher in minocycline-exposed female $F O X O$-null mutants (lower panel). For male flies, $\mathrm{n}=119$ (normal), $\mathrm{n}=136$ $(0.05 \mathrm{mM}), \mathrm{n}=135(0.36 \mathrm{mM}) ; p=0.0471$ (normal vs. $0.05 \mathrm{mM}), p=0.7333$ (normal vs. $0.36 \mathrm{mM}$ ). For female flies, $\mathrm{n}=111$ (normal), $\mathrm{n}=105(0.05 \mathrm{mM}), \mathrm{n}=122(0.36 \mathrm{mM}) ; p=0.0275$ (normal vs. $0.05 \mathrm{mM}), p=0.0002$ (normal vs. $0.36 \mathrm{mM}$ ). $p$-values for lifespan curves were calculated by the log-rank test. All lifespan experiments were repeated with similar results; representative experiments are shown. 
A
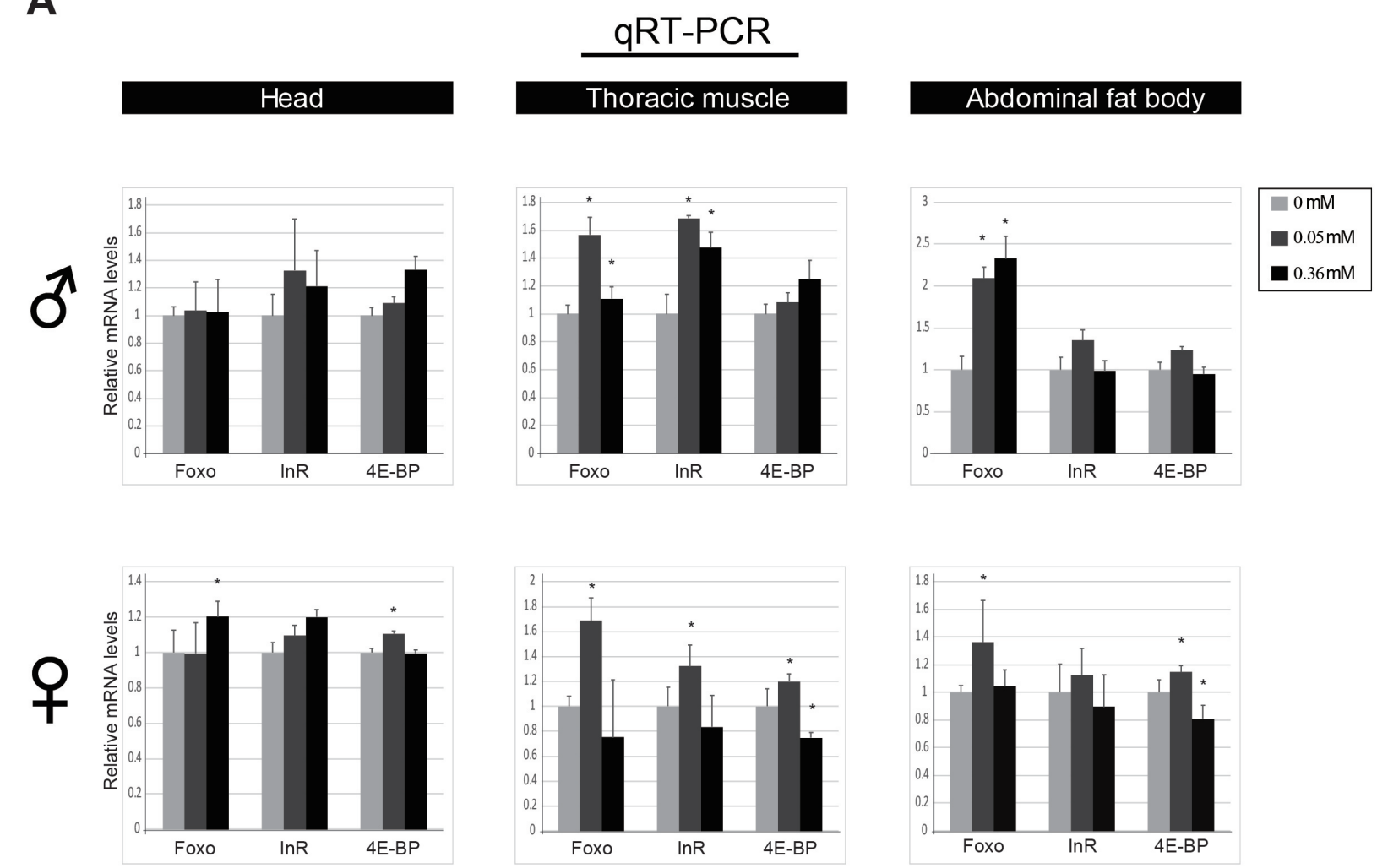

B

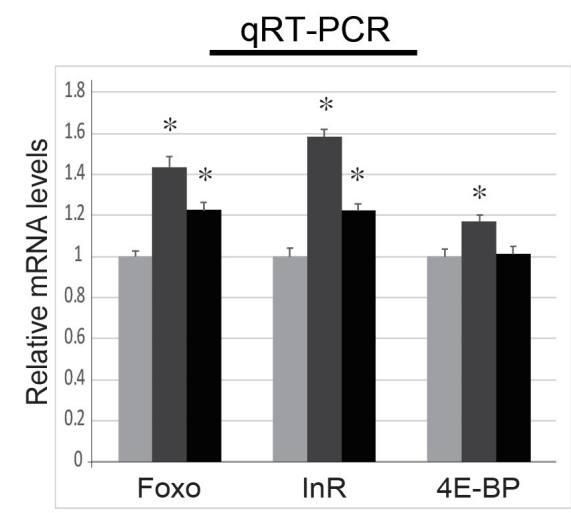

C

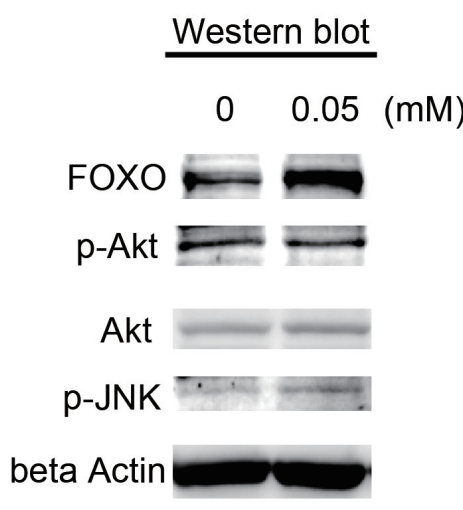

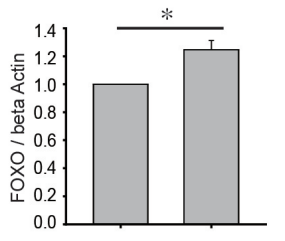
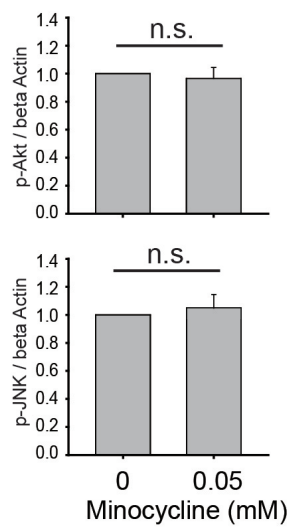

Figure 7: Minocycline treatment increase FOXO activity. (A) Minocycline treatment for 3 days frequently increases mRNA expression of FOXO and its target genes such as InR and $4 E-B P$. This phenotype is broadly seen across the tissues including head (left panel), thoracic muscle (middle panel), and abdominal fat body tissues (right panel), and is also consistently seen in both male ( $\widehat{O})$ and female (+) flies. $n=18$ (head), $n=10$ (thoracic muscle), and n=10 (abdominal fat body) per treatment. (B) Representation of minocycline's influence on mRNA expression of FOXO, InR and $4 E-B P$ by pooling individual data sets separated by tissues and sexes shown in panel A. (C) Minocycline treatment increases the expression of FOXO protein but marginally affects Akt and JNK activity shown by western blot (left panel) and its quantification (right panel). Flies were treated with hydrogen peroxide and indicated concentrations of minocycline for 2 days and abdominal fat bodies were prepared. Similar results were seen in head and thoracic muscle tissues. Three biological replicates were analyzed. Data are presented as mean \pm SEM. ${ }^{*} \mathrm{p}<0.05$ when compared to the respective controls (t-test). n.s., not significant. 
cellular apoptosis [27]. Increased production of ROS in numerous pathological conditions may aggravate cellular homeostasis and damage the cell [28]. Because of its multi-substituted phenol ring, minocycline can scavenge free radicals, protecting against oxidative stress [29]. However, our results provide an alternative explanation for the oxidative stress resistance induced by minocycline: The drug increases the activity of the FOXO transcription factor in animal cells, thereby rendering the organism more resistant to oxidative stress. In line with this, minocycline has also been shown to inhibit some enzymes, such as metalloproteinases and oxygenases, that generate ROS $[30,31]$, which might explain the marginal increase in oxidative stress resistance induced by minocycline seen in FOXO null mutant (Figure 6B).

Our findings may also provide a plausible explanation for other non-antibiotic effects of minocycline. The drug has been shown to have tumor-suppressive properties in leukemia, prostate cancer, and ovarian cancers [32-34], which may be partly explained by minocycline's effect on activating FOXO, a well-known tumor suppressor. Future studies should characterize the molecular mechanism responsible for minocycline's effect on FOXO activity.

\section{MATERIALS AND METHODS}

\section{Fly rearing and lifespan measurement}

The Drosophila melanogaster strains, $w^{1118}$, Canton S, UAS-FOXO, heat shock Gal4 (HS-Gal4) were obtained from Bloomington stock center (University of Indiana, Bloomington). FOXO'2rev6A is the $F O X O$ null allele in which 2nd site lethal mutation was removed from $F O X O^{21}$ (A gift from Dr. Marc Tatar). All flies used in this study were reared on the same diet and same environmental conditions: ambient temperature of $25^{\circ} \mathrm{C}$, with $60 \%$ humidity and 12-h light and dark cycles, on standard yeastglucose medium $(86.2 \mathrm{~g} / \mathrm{L}$ glucose, $40.8 \mathrm{~g} / \mathrm{L}$ cornmeal, $62.4 \mathrm{~g} / \mathrm{L}$ dried yeast, and $9.3 \mathrm{~g} / \mathrm{L}$ agar. Tegosept and propionic acid were added as preservatives). Minocycline stock solution $(45 \mathrm{mM})$ was prepared by dissolving minocycline hydrochloride (M9511, Sigma Aldrich) in distilled water and mixed in medium with appropriate final concentrations. Tetracycline stock solution $(45 \mathrm{mM})$ were similarly prepared (T7660, Sigma Aldrich). More than 210 flies per treatment were collected at 3 days after eclosion with the distribution of 15 flies per vial. Dead flies were counted every $3 \mathrm{~d}$, when remaining flies were transferred to fresh food vials, a practice that was continued until all flies were dead. This process constituted one biological replicate, and was repeated at least three times to yield three independent biological replicates. Lifespan and mortality rate analyses were performed using Online Application for the Survival Analysis of lifespan assays
2 (OASIS 2) [35] and the p values were calculated using the log-rank test.

\section{Establishment of germ-free fly}

Germ-free flies were made according to the method described in a previous study [36] with slight modification: Germ-free animals were generated by decontaminating dechorionated embryos for $1 \mathrm{~min} 30 \mathrm{sec}$ in $2.7 \%$ sodium hypochlorite. Embryos were subsequently washed twice in $70 \%$ ethanol, followed by three washes with sterile water. The embryos were then maintained with axenic foods and routinely checked for bacterial contamination by culturing the homogenates on nutrient-agar plates.

\section{Measurements of food intake}

A food intake assay was performed following the method described in a previous study [37] with slight modification: Flies were cultured for 90 minutes in food containing $0.5 \%$ Bromophenol Blue. 10 fly bodies were homogenized in distilled water and supernatant was used for measuring the absorbance at $625 \mathrm{~nm}$. Three biological replicates were analyzed per treatment.

\section{Measurements of fecundity}

15 female flies were used per batch and male flies were removed after 3 days of mating. Each vial contained one female fly and it was transferred every three days to fresh food vial. The number of eggs laid was counted every three days until no egg was laid. The experiment was repeated to yield three biological replicates per treatment.

\section{Measurements of locomotor activity}

Climbing ability of flies was measured by using rapid iterative negative geotaxis (RING) assay [38] with slight modifications. Adult fruit flies were exposed to normal food or minocycline contaminated food and then transferred to new vials -15 males and 15 females in each vial. These vials were loaded into the equipment and tapped on a table three times in rapid succession to initiate a negative geotaxis response. The positions of flies were captured by a digital camera $5 \mathrm{sec}$ after initiation of behavior, and the number of flies that climbed above the standards (30 $\mathrm{mm}$ from the bottom) was counted. After each trial, the flies were allowed 1 min of recovery from shock. These cycles were conducted three times with 10 replicates in each group.

\section{Measurements of resistance to hydrogen peroxide}

1-day-old flies of the indicated genotypes were mated for 3 days, then were segregated by females and 
males. The flies were transferred to medium containing $3 \%$ hydrogen peroxide (H0298, Samchun chemical) and various concentrations $(0 \mathrm{mM}, 0.05 \mathrm{mM}$, or $0.36 \mathrm{mM})$ of minocycline. Dead flies were counted once a day. The experiment was repeated to yield three biological replicates per treatment.

\section{RNA preparation and quantitative RT-PCR (qRT-PCR)}

Adult flies previously anaesthetized by ice were dissected in $70 \%$ ethanol. Head and thorax were separated and prepared. Abdominal fat bodies were prepared by removing midgut and gonadal tissues from abdominal carcasses. Prepared samples were quickly transferred to Trizol solution (RNAiso Plus, Takara) and ground for RNA preparation. RNA was extracted following the manufacturer's recommended instructions. cDNAs were synthesized using RevertAid Reverse Transcriptase (Thermo Scientific). PCR was performed using the CFX Connect Real-Time PCR Detection System (Bio-Rad) and SYBR Premix Ex Taq (TaKaRa). All interested mRNA levels were calculated as a relative fold-change over $R p 49$ mRNA. The comparative cycle threshold $(\mathrm{Ct})$ method was applied to estimate mRNA levels. The following PCR primers were used: InR, 5'-GGA TGC GTG ATC GAT AAG AA-3' and 5'-CTG ATA ATA GCC TTT CGG ACA G-3'; 4E-BP, 5'ATG CAG CAA CTG CCA AAT C-3' and 5'-CCG AGA GAA CAA ACA AGG TGG-3'; FOXO, 5'-CAG AAT GCG AAT GCA GCC AA - $3^{\prime}$ and 5'-CCA ATG GCA TGC GTG ATG AG-3'; Rp49, 5'-AGG GTA TCG ACA ACA GAG TG-3' and 5'-CAC CAG GAA CTT CTT GAA TC-3'.

\section{Western blot}

Head, thorax and abdomen in adult fly were homogenized in RIPA lysis buffer (Thermo Fisher Scientific, Cat. \# 89900) containing the protease and phosphatase inhibitor cocktail (Thermo Fisher Scientific, Cat. \# 78449). The isolated protein samples pooled from 25 flies, were quantified by the Bradford assay and separated in $10 \%$ poly-acrylamide gel. The transferred Immobilon $^{\mathrm{TM}}$ PVDF Membrane (Millipore) was blocked for $1 \mathrm{~h}$ at room temperature (RT) in TBST containing 5\% BSA and incubated overnight at $4{ }^{\circ} \mathrm{C}$. The anti-phosphoAKT (Cell signaling, Cat. \#4054), anti-pan-AKT (Cell signaling, Cat. \#9272), anti-phospho-JNK (Cell signaling, Cat. \#9255) anti-dFOXO (Cosmo Bio, Cat. THU-ADFOXO), and anti-Actin (Cell signaling, Cat. \#4967) was diluted to $1: 1000$ with 5\% BSA in TBST when used as a primary antibody. After washing, the membrane was incubated with 5\% skim milk in TBST containing HRP-conjugated secondary antibody (1:10000) at RT for $1 \mathrm{~h}$. The HRP signal was generated following the ECL substrate treatment and analyzed by the ChemiDoc miniHD6 system (UVITEC).

\section{ACKNOWLEDGMENTS}

We are very grateful to Dr. Marc Tatar for sharing the FOXO-null fly. We thank the Bloomington Drosophila Stock Center. We thank Gangsik Han for helping fecundity test.

\section{CONFLICTS OF INTEREST}

The authors declare that they have no competing financial interests.

\section{FUNDING}

This research was supported by the Basic Science Research Program through the National Research Foundation of Korea (NRF), funded by the Ministry of Education, Science and Technology (Grant number: 2014R1A2A1A11052915), and by a grant from the Korea Health Technology R\&D Project through the Korea Health Industry Development Institute (KHIDI), funded by the Ministry of Health \& Welfare, Republic of Korea (Grant number: HI14C2380).

\section{REFERENCES}

1. Good ML, Hussey DL. Minocycline: stain devil? Br J Dermatol. 2003; 149:237-9.

2. Yong VW, Wells J, Giuliani F, Casha S, Power C, Metz LM. The promise of minocycline in neurology. Lancet Neurol. 2004; 3:744-51.

3. Klein NC, Cunha BA. Tetracyclines. Med Clin North Am. 1995; 79:789-801.

4. Brogden RN, Speight TM, Avery GS. Minocycline: A review of its antibacterial and pharmacokinetic properties and therapeutic use. Drugs. 1975; 9:251-91.

5. Saivin S, Houin G. Clinical pharmacokinetics of doxycycline and minocycline. Clin Pharmacokinet. 1988; 15:355-66.

6. Sapadin AN, Fleischmajer R. Tetracyclines: nonantibiotic properties and their clinical implications. J Am Acad Dermatol. 2006; 54:258-65.

7. Golub LM, Ramamurthy NS, McNamara TF, Greenwald RA, Rifkin BR. Tetracyclines inhibit connective tissue breakdown: new therapeutic implications for an old family of drugs. Crit Rev Oral Biol Med. 1991; 2:297-321.

8. Greenwald R, Golub LM. Tetracyclines in arthritis. J Rheumatol. 1993; 20:1990.

9. Kielian T, Esen N, Liu S, Phulwani NK, Syed MM, Phillips N, Nishina K, Cheung AL, Schwartzman JD, Ruhe JJ. Minocycline modulates neuroinflammation independently of its antimicrobial activity in staphylococcus aureusinduced brain abscess. Am J Pathol. 2007; 171:1199-214.

10. Griffin MO, Fricovsky E, Ceballos G, Villarreal F. Tetracyclines: a pleitropic family of compounds with promising therapeutic properties. Review of the literature. Am J Physiol Cell Physiol. 2010; 299:C539-48. 
11. Soory M. A role for non-antimicrobial actions of tetracyclines in combating oxidative stress in periodontal and metabolic diseases: a literature review. Open Dent J. 2008; 2:5-12.

12. Lampl Y, Boaz M, Gilad R, Lorberboym M, Dabby R, Rapoport A, Anca-Hershkowitz M, Sadeh M. Minocycline treatment in acute stroke- An open-label, evaluator-blinded study. Neurology. 2007; 69:1404-10.

13. Du YS, Ma ZZ, Lin SZ, Dodel RC, Gao F, Bales KR, Triarhou LC, Chernet E, Perry KW, Nelson DLG, Luecke $\mathrm{S}$, Phebus LA, Bymaster FP, et al. Minocycline prevents nigrostriatal dopaminergic neurodegeneration in the MPTP model of Parkinson's disease. Proceedings of the National Academy of Sciences of the United States of America. 2001; 98:14669-74.

14. Thomas M, Le WD. Minocycline: Neuroprotective mechanisms in Parkinson's disease. Current Pharmaceutical Design. 2004; 10:679-86.

15. Chen M, Ona VO, Li MW, Ferrante RJ, Fink KB, Zhu S, Bian J, Guo L, Farrell LA, Hersch SM, Hobbs W, Vonsattel JP, Cha JHJ, et al. Minocycline inhibits caspase-1 and caspase- 3 expression and delays mortality in a transgenic mouse model of Huntington disease. Nature Medicine. 2000; 6:797-801.

16. Zhu S, Stavrovskaya IG, Drozda M, Kim BYS, Ona V, Li MW, Sarang S, Liu AS, Hartley DM, Du CW, Gullans S, Ferrante RJ, Przedborski S, et al. Minocycline inhibits cytochrome $\mathrm{c}$ release and delays progression of amyotrophic lateral sclerosis in mice. Nature. 2002; 417:74-8.

17. Choi Y, Kim HS, Shin KY, Kim EM, Kim M, Kim HS, Park CH, Jeong YH, Yoo J, Lee JP, Chang KA, Kim S, Suh YH. Minocycline attenuates neuronal cell death and improves cognitive impairment in Alzheimer's Disease models. Neuropsychopharmacology. 2007; 32:2393-404.

18. Lopez-Otin C, Blasco MA, Partridge L, Serrano M, Kroemer G. The hallmarks of aging. Cell. 2013; 153:1194-217.

19. Kenyon CJ. The genetics of ageing. Nature. 2010; 464:504-12.

20. Reiter LT, Potocki L, Chien S, Gribskov M, Bier E. A systematic analysis of human disease-associated gene sequences in Drosophila melanogaster. Genome Res. 2001; 11:1114-25.

21. Mackenzie SM, Brooker MR, Gill TR, Cox GB, Howells AJ, Ewart GD. Mutations in the white gene of Drosophila melanogaster affecting $\mathrm{ABC}$ transporters that determine eye colouration. Biochim Biophys Acta. 1999; 1419:173-85.

22. Oxenkrug G, Navrotskaya V, Vorobyova L, Summergrad P. Minocycline effect on life and health span of Drosophila melanogaster. Aging Dis. 2012; 3:352-9.

23. Oxenkrug GF. The extended life span of Drosophila melanogaster eye-color (white and vermilion) mutants with impaired formation of kynurenine. J Neural Transm (Vienna). 2010; 117:23-6.

24. Mora M, Medina-Leendertz SJ, Bonilla E, Teran RE, Paz MC, Arcaya JL. Minocycline, but not ascorbic acid, increases motor activity and extends the life span of Drosophila melanogaster. Invest Clin. 2013; 54:161-70.

25. Partridge L, Bruning JC. Forkhead transcription factors and ageing. Oncogene. 2008; 27:2351-63.

26. Golub L, Greenwald R, Ramamurthy N, Zucker S, Ramsammy L, McNamara T. Tetracyclines (TCs) inhibit matrix metalloproteinases (MMPs): in vivo effects in arthritic and diabetic rats and new in vitro studies. Matrix Suppl. 1992; 1:315-6.

27. Sancho M, Herrera AE, Gortat A, Carbajo RJ, PinedaLucena A, Orzaez M, Perez-Paya E. Minocycline inhibits cell death and decreases mutant Huntingtin aggregation by targeting Apaf-1. Human Molecular Genetics. 2011; 20:3545-53.

28. Park JL, Lucchesi BR. Mechanisms of myocardial reperfusion injury. Annals of Thoracic Surgery. 1999; 68:1905-12.

29. Webster G, Del Rosso JQ. Anti-inflammatory activity of Tetracyclines. Dermatologic Clinics. 2007; 25:133-135.

30. Griffin MO, Ceballos G, Villarreal FJ. Tetracycline compounds with non-antimicrobial organ protective properties: Possible mechanisms of action. Pharmacological Research. 2011; 63:102-7.

31. Yrjanheikki J, Tikka T, Keinanen R, Goldsteins G, Chan $\mathrm{PH}$, Koistinaho J. A tetracycline derivative, minocycline, reduces inflammation and protects against focal cerebral ischemia with a wide therapeutic window. Proceedings of the National Academy of Sciences of the United States of America. 1999; 96:13496-500.

32. van den Bogert C, Dontje BH, Kroon AM. The antitumour effect of doxycycline on a T-cell leukaemia in the rat. Leuk Res. 1985; 9:617-23.

33. Selzer MG, Zhu B, Block NL, Lokeshwar BL. CMT-3, a chemically modified tetracycline, inhibits bony metastases and delays the development of paraplegia in a rat model of prostate cancer. Ann N Y Acad Sci. 1999; 878:678-82.

34. Pourgholami MH, Mekkawy AH, Badar S, Morris DL. Minocycline inhibits growth of epithelial ovarian cancer. Gynecol Oncol. 2012; 125:433-40.

35. Han SK, Lee D, Lee H, Kim D, Son HG, Yang JS, Lee SV, Kim S. OASIS 2: online application for survival analysis 2 with features for the analysis of maximal lifespan and healthspan in aging research. Oncotarget. 2016; 7:5614756152. http://doi.org/10.18632/oncotarget.11269.

36. Ryu JH, Kim SH, Lee HY, Bai JY, Nam YD, Bae JW, Lee DG, Shin SC, Ha EM, Lee WJ. Innate immune homeostasis by the homeobox gene caudal and commensal-gut mutualism in Drosophila. Science. 2008; 319:777-82.

37. Sun Y, Yolitz J, Wang C, Spangler E, Zhan M, Zou S. Aging studies in Drosophila melanogaster. Methods Mol Biol. 2013; 1048:77-93.

38. Gargano JW, Martin I, Bhandari P, Grotewiel MS. Rapid iterative negative geotaxis (RING): a new method for assessing age-related locomotor decline in Drosophila. Exp Gerontol. 2005; 40:386-95. 